\title{
Near-Infrared Upconversion Transparent Inorganic Nanofilm: Confined-Space Directed Oriented Crystal Growth and Distinctive Ultraviolet Emission
}

Xiaoxia Liu, ${ }^{\dagger, \S, \perp}$ Yaru Ni, ${ }^{\dagger \dagger, \S, \perp^{\perp l}}$ Cheng Zhu, ${ }^{\dagger, \S, \perp}$ Liang Fang, ${ }^{\dagger, \S, \perp}$ Song Hu,,$^{\dagger, \S, \perp}$ Zhitao Kang, ${ }^{\ddagger}$ Chunhua $L u,{ }^{*}, \dagger, \S, \perp$ and Zhongzi X $u^{\dagger, \S, \perp}$

${ }^{\dagger}$ State Key Laboratory of Materials-Orient Chemical Engineering, College of Materials Science and Engineering, Nanjing Tech University, Nanjing 210096, P. R. China.

${ }^{\S}$ Jiangsu Collaborative Innovation Center for Advanced Inorganic Function

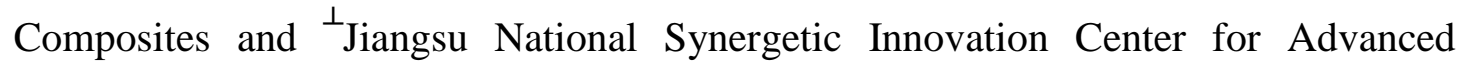
Materials (SICAM), Nanjing Tech University, Nanjing 210009, P. R. China.

"Key Laboratory of MEMS of Ministry of Education, Southeast University, Nanjing 210009, P. R. China.

*Electro-Optical Systems Laboratory, Georgia Tech Research Institute, Georgia Institute of Technology, Atlanta, Georgia 30332, United States.

*E-mail: chhlu@njtech.edu.cn,

*E-mail: nyr@njtech.edu.cn. 


\section{Methods}

Synthesis of hydrothermal precursor solution of $\mathrm{NaYF}_{4}: \mathrm{Yb}, \mathrm{Tm}$ with different concentrations

In a typical hydrothermal synthesis of $\mathrm{NaYF}_{4}: 20 \% \mathrm{Yb}^{3+}, 0.5 \% \mathrm{Tm}^{3+}$ upconversion precursor, 2 mmol $\mathrm{RECl}_{3} \cdot 6 \mathrm{H}_{2} \mathrm{O}, 2 \mathrm{mmol}$ sodium oleate $(\mathrm{NaOA})$ and $50 \mathrm{mmol} \mathrm{NaF}$ were dissolved in $10 \mathrm{~mL}, 20 \mathrm{ml}$ and $30 \mathrm{ml}$ of distilled water, respectively. The rare earth chloride solution was then added dropwise into $\mathrm{NaOA}$ solution along with vigorous stirring for $40 \mathrm{~min}$. $\mathrm{NaF}$ solution was then added into above solution and the mixture was stirred for another $30 \mathrm{~min}$ to form the precursor which was labelled as $\mathrm{c} 2$ : $2 \mathrm{mmol} / 60 \mathrm{ml}$ in molar concentration of RE ions. The precursors synthesis with half and 1.5-fold concentration of $\mathrm{c} 2$ are labelled as $\mathrm{c} 1(1 \mathrm{mmol} / 60 \mathrm{ml})$ and $\mathrm{c} 3(3 \mathrm{mmol} /$ $60 \mathrm{ml}$ ), respectively.

\section{Synthesis of $\mathrm{NaYF}_{4}: \mathrm{Yb}, \mathrm{Tm}$ nanoparticles by hydrothermal method}

In a typical hydrothermal synthesis of $\mathrm{NaYF}_{4}: 20 \% \mathrm{Yb}^{3+}, 0.5 \% \mathrm{Tm}^{3+}$ upconversion nanoparticles, the as-prepared precursor solution was transferred into the PPL vessel and sealed in a stainless steel autoclave. The autoclave was heated at $220{ }^{\circ} \mathrm{C}$ for $24 \mathrm{~h}$. After the autoclave was cooled to room temperature naturally, the precipitates were collected by centrifugation and washed with distilled water and ethanol for 4 times, and dried at $60{ }^{\circ} \mathrm{C}$ for $12 \mathrm{~h}$.

The specific $\mathrm{NaYF}_{4}$ powders mentioned in the paper grown for $1 \mathrm{~h}$ and $6 \mathrm{~h}$ and precursor were obtained by fast cooling of the autoclave within $5 \mathrm{~min}$ to room temperature and freezing drying.

\section{Synthesis of $\beta$-NaYF 4 :Yb,Tm nanoparticles by hydrothermal method}

In the synthesis of $\beta-\mathrm{NaYF}_{4}: 20 \% \mathrm{Yb}^{3+}, 0.5 \% \mathrm{Tm}^{3+}$ upconversion nanoparticles, the autoclave was heated at $230{ }^{\circ} \mathrm{C}$ for $24 \mathrm{~h}$. The precipitates were collected after the autoclave was cooled to room temperature by centrifugation and washed with distilled water and ethanol for 4 times, and dried at $60^{\circ} \mathrm{C}$ for $12 \mathrm{~h}$.

Synthesis of $\beta-\mathrm{NaYF}_{\mathbf{4}}: \mathbf{Y b}, \mathbf{T m}$ nanoparticles by thermal decomposition method

The hexagonal $\mathrm{NaYF}_{4}: 20 \% \mathrm{Yb}^{3+}, 0.5 \% \mathrm{Tm}^{3+}$ nanoparticles employed in this study were prepared with thermal decomposition method. In a typical synthesis, $3 \mathrm{mmol}$ $\mathrm{RECl}_{3} \cdot 6 \mathrm{H}_{2} \mathrm{O}(\mathrm{Ln}=\mathrm{Y}, \mathrm{Yb}, \mathrm{Tm})$ and $30 \mathrm{~mL}$ of ODE and $30 \mathrm{~mL}$ of OA were added into a $100 \mathrm{~mL}$ three-necked flask and heated to $160{ }^{\circ} \mathrm{C}$ under high-purity $\mathrm{N}_{2}$ flow with magnetic stirring for $45 \mathrm{~min}$. The solution was cooled down to $60{ }^{\circ} \mathrm{C}$, and $20 \mathrm{ml}$ of methanol solution which contains $12 \mathrm{mmol}$ of $\mathrm{NH}_{4} \mathrm{~F}$ and $7.5 \mathrm{mmol}$ of $\mathrm{NaOH}$ was added dropwise with a gentle flow of $\mathrm{N}_{2}$. After $20 \mathrm{~min}$ for nucleation reaction, the vessel was heated to $100{ }^{\circ} \mathrm{C}$ and maintained for $10 \mathrm{~min}$ and then up to $310{ }^{\circ} \mathrm{C}$ for crystal growth under a gentle high-purity $\mathrm{N}_{2}$ flow for $60 \mathrm{~min}$., and The nanoparticles were precipitated after the solution was cooled down to room temperature by adding $20 \mathrm{ml}$ of ethanol and magnetic stirring for $5 \mathrm{~min}$ and then collected by centrifugation and washed with ethanol for four times.

\section{Self-assembly film of thermal decomposition $\mathrm{NaYF}_{4}: \mathrm{Yb}, \mathrm{Tm}$ nanoparticles}

The $\beta-\mathrm{NaYF}_{4}: 20 \% \mathrm{Yb}^{3+}, 0.5 \% \mathrm{Tm}^{3+}$ nanoparticles were self-assembly on glass substrates via modified interfacial self-assembly method ${ }^{1} .5 \mathrm{mg}$ of nanoparticles were dispersed in $1.5 \mathrm{~mL}$ of cyclohexane. A few milliliter of ethylene glycol was spread in 
a Teflon groove of $1.5 \times 1.5 \times 1 \mathrm{~cm}^{3}$ and $15 \mu \mathrm{l}$ of nanoparticles dispersed solution was added dropwise. Cyclohexane was slowly volatilized at $25^{\circ} \mathrm{C}$. The film was then transferred onto the cleansed glass and heated up to $120{ }^{\circ} \mathrm{C}$ to volatilize ethylene glycol. The film was obtained after about $2 \mathrm{~h}$.

\section{PDMS film composited with thermal decomposition $\mathrm{NaYF}_{4}: \mathrm{Yb}, \mathrm{Tm}$ nanoparticles}

$5 \mathrm{mg}$ of $\beta-\mathrm{NaYF}_{4}: 20 \% \mathrm{Yb}^{3+}, 0.5 \% \mathrm{Tm}^{3+}$ nanoparticles were dispersed in $1 \mathrm{~mL}$ of xylene. The solution was then added dropwise into $5.7 \mathrm{~g}$ PDMS with magnetic stirring for $10 \mathrm{~min} .0 .57 \mathrm{~g}$ curing agent was then added dropwise with magnetic stirring for $5 \mathrm{~min}$. The PDMS composite film was deposited on a silica glass by dip-coating and then annealed at $60{ }^{\circ} \mathrm{C}$.

\section{OA-Y complex film combined with a quartz glass}

$\mathrm{NaOA}$ and $\mathrm{YCl}_{3}$ were separately dissolved in $30 \mathrm{ml}$ distilled water and $\mathrm{YCl}_{3}$ aqueous solution was then dropwise added into the $\mathrm{NaOA}$ solution with magnetic stirring to form OA-Y complex. After $40 \mathrm{~min}$, the mixture was transferred into a $100 \mathrm{ml}$ PPL vessel in which two superimposed silica glasses were placed. The vessel was then sealed with a stainless steel case and heated up to $220{ }^{\circ} \mathrm{C}$ for $24 \mathrm{~h}$. The obtained "silica glasses" (named as OA/Silica Glass) were taken out after the vessel was cooled down to room temperature and ultrasonic cleaned with ethanol for 4 times.

\section{PMMA sheet cured between superimposed silica glass substrates}

$10 \mathrm{~g}$ MMA and $0.05 \mathrm{~g}$ AIBN initiator were mixed in a $20 \mathrm{ml}$ glass bottle and magnetic stirred for $30 \mathrm{~min}$ at $60{ }^{\circ} \mathrm{C} .0 .5 \mathrm{~g}$ EDMA crosslinking agent was then dropwise added into the bottle. The mixture was stirred for $90 \mathrm{~min}$ to form a homogeneous solution. Two clean silica glasses were superimposed in a $1.5 \times 1.5 \times 1 \mathrm{~cm}^{3}$ Teflon groove. After the solution was cooled down to room temperature, $1.5 \mathrm{ml}$ solution was dropwise added into the groove which is then covered with a glass slide to reduce volatilization and heated up to $85^{\circ} \mathrm{C}$ and maintained for $8 \mathrm{~h}$ to promote curing. A thin PMMA sheet can be obtained between silica glass substrates. 


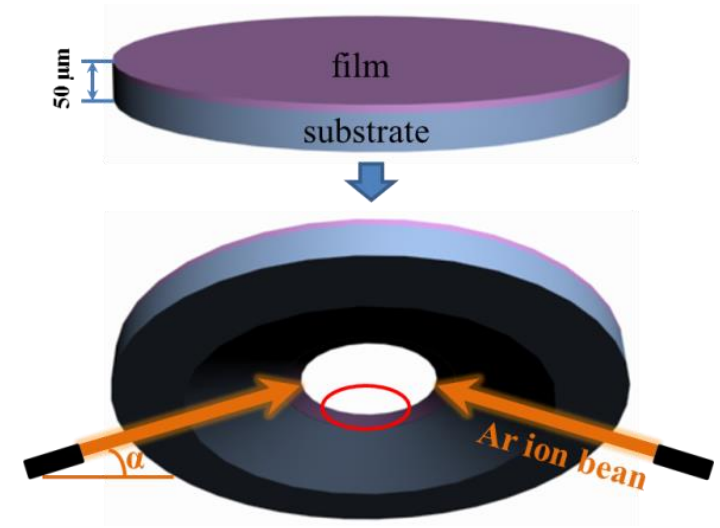

Schematic S1 Schematic diagram of sample preparation process for TEM of composited UC films.

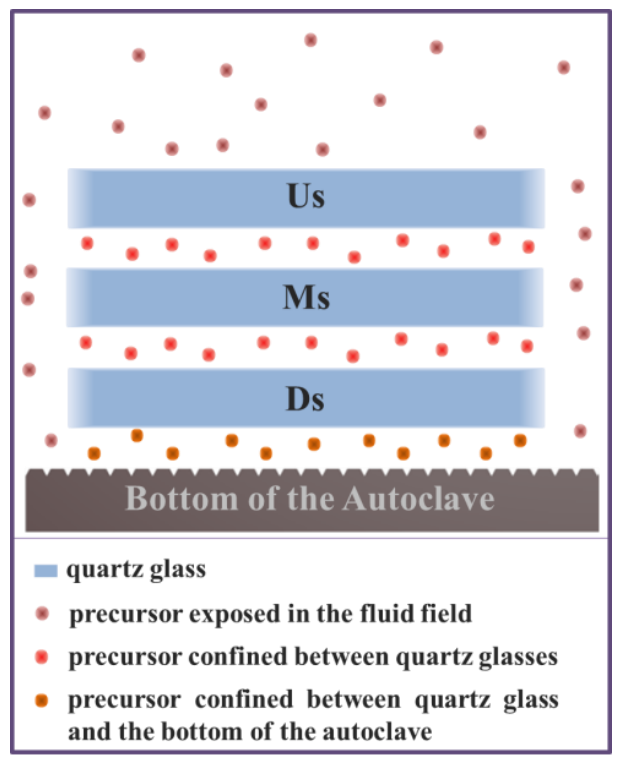

Schematic S2 Schematic diagram of space-confined growth of UC inorganic films by hydrothermal method (the three superimposed substrates are labelled as Us, Ms, and Ds, up to down).
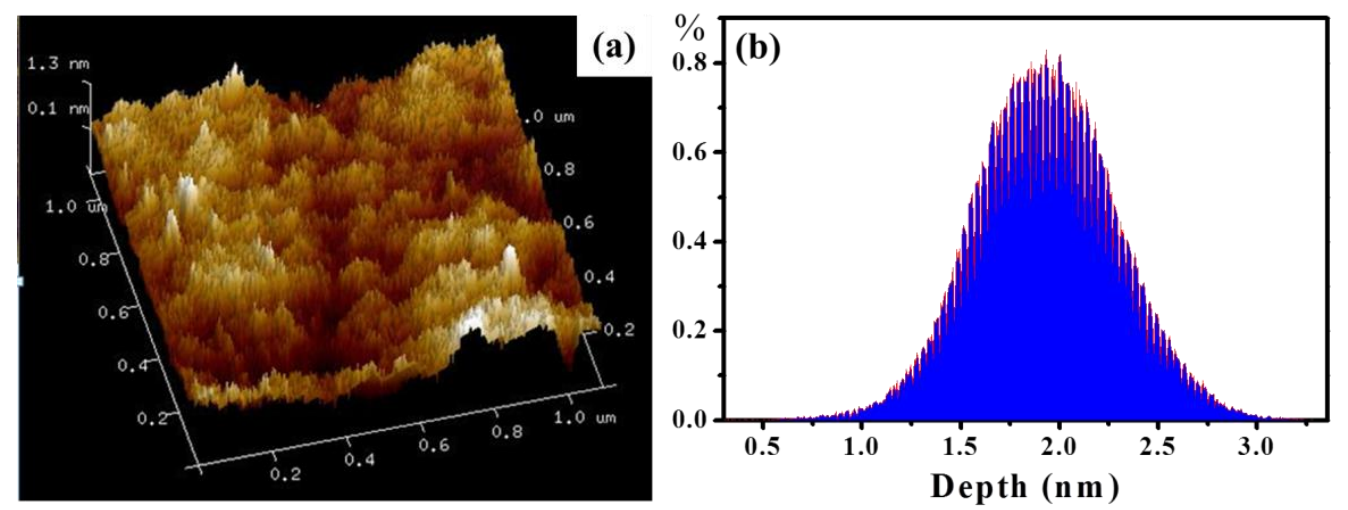

Figure S1 (a) AFM image of a silica glass surface. (b) Depth pattern of (a). 

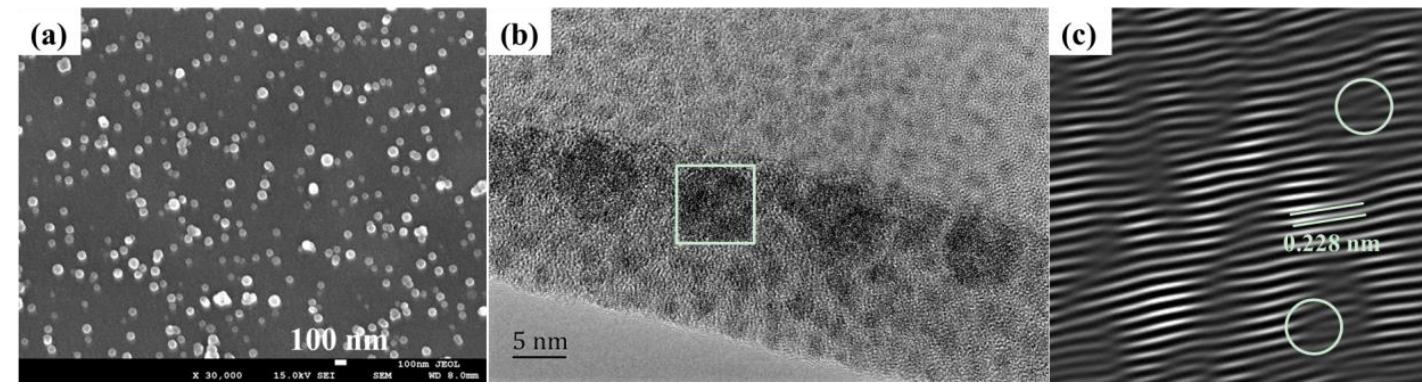

Figure S2 (a) FESEM image of Uf. (b) TEM image of Uf. (c) The lattice fringe image of the selected district in (b) with the interplanar spacing of $0.228 \mathrm{~nm}$, which corresponds to (111) atomic planes of hexagonal $\mathrm{NaYF}_{4}$ crystal structure.
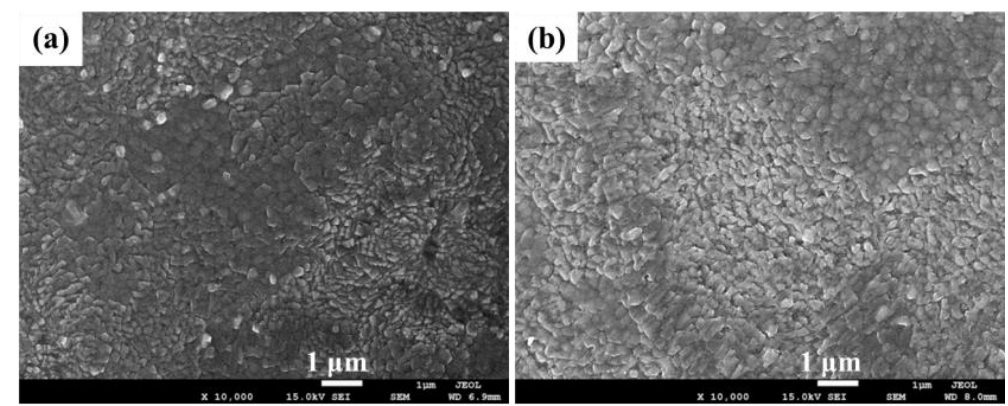

(c)

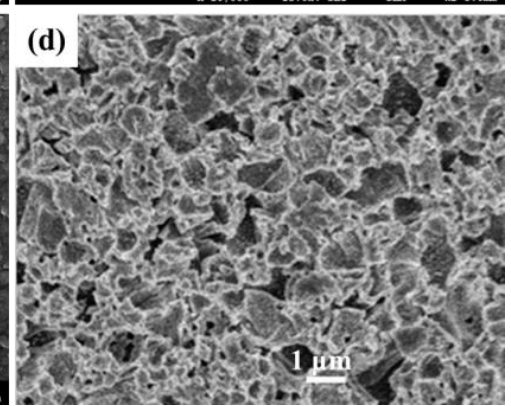

Figure S3 FESEM images of $\mathrm{NaYF}_{4}: 20 \mathrm{Yb}, 0.5 \mathrm{Tm}$ UC films of (a) lower surface of Uf, (b) lower surface of Mf, (c) upper surface of Df, and (d) lower surface of Df, respectively. 

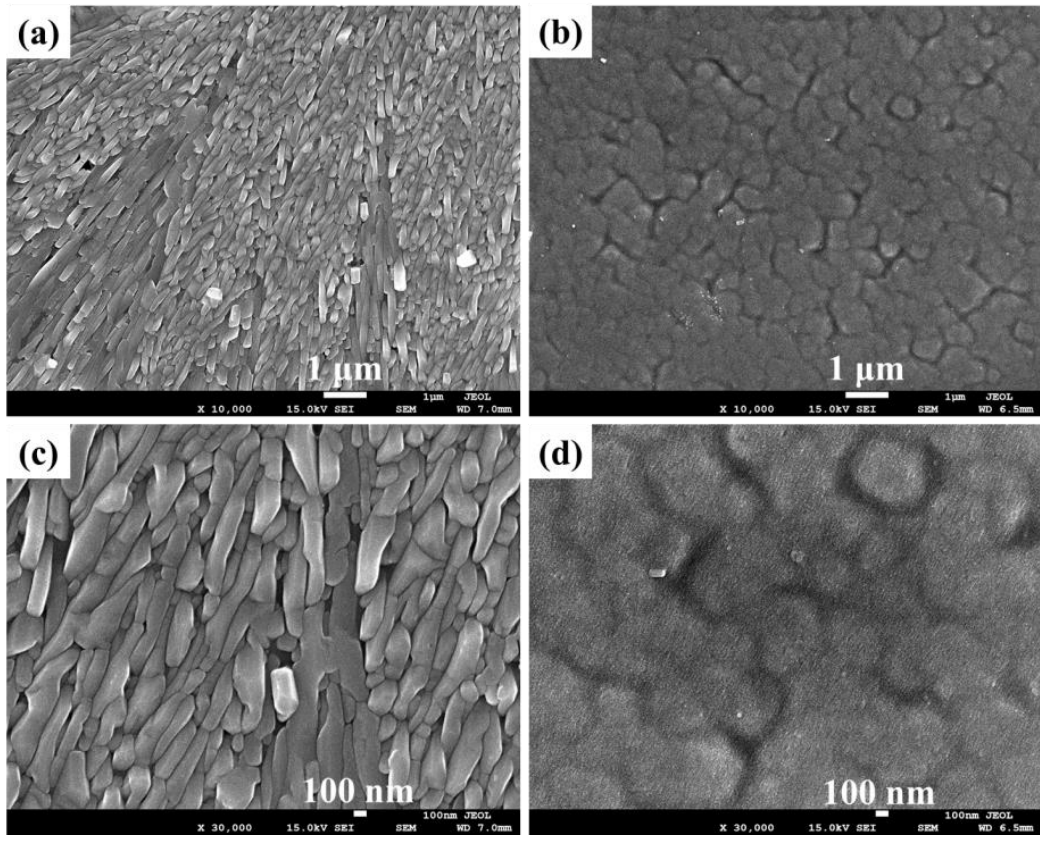

(d)

Figure S4 FESEM images of upper-surface of (a) $\mathrm{NaLuF}_{4}: 20 \mathrm{Yb}, 0.5 \mathrm{Tm}$ and (b) $\mathrm{NaGdF}_{4}: 20 \mathrm{Yb}, 0.5 \mathrm{Tm} \mathrm{UC}$ films, (c, d) are local enlarged views of (a, b), respectively.
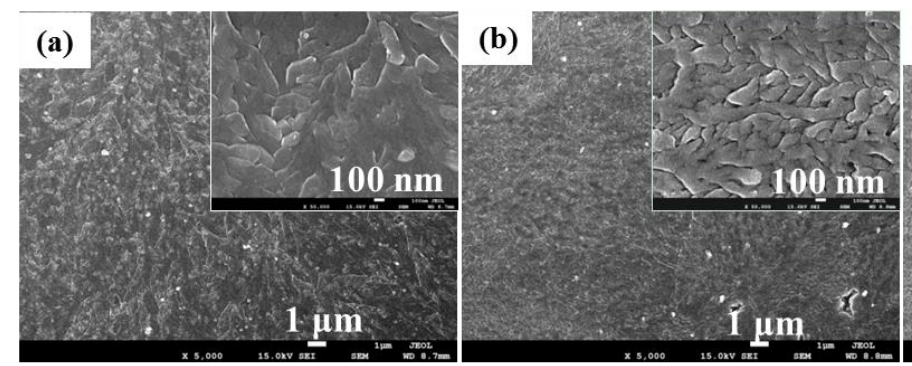

(c)
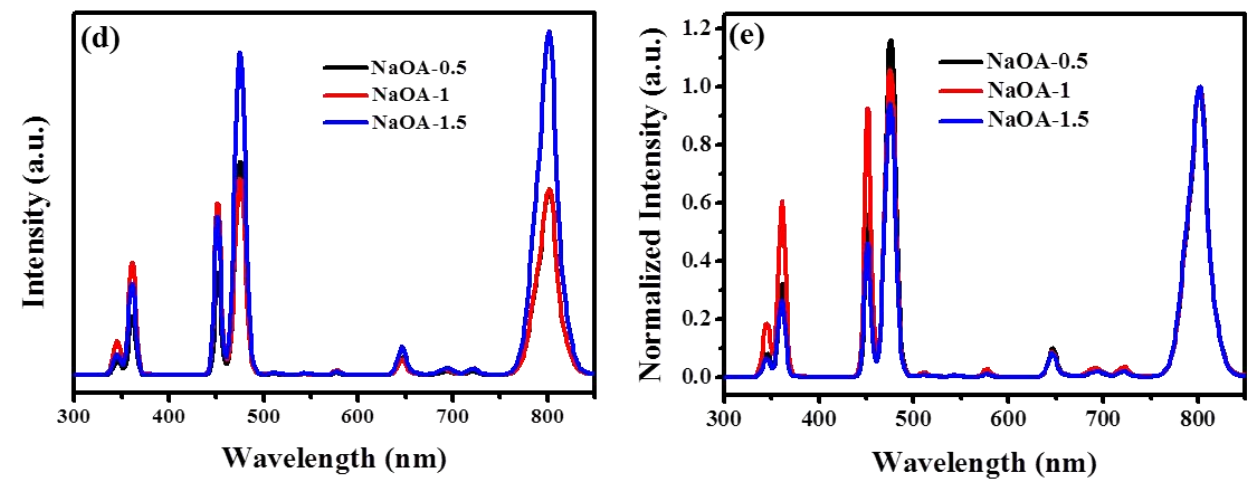

Figure S5 FESEM images of $\mathrm{NaYF}_{4}: 20 \mathrm{Yb}, 0.5 \mathrm{Tm}$ UC films with different molar ratio of $\mathrm{NaOA}$ and RE ions of (a) 0.5, (b) 1 and (c) 1.5, which are labelled as NaOA-0.5, NaOA-1 and NaOA-1.5. (d) UC fluorescence spectra of NaOA-0.5, NaOA-1 and $\mathrm{NaOA}-1.5$, and (e) corresponding spectra after normalized at $802 \mathrm{~nm}$. Excitation is from $980 \mathrm{~nm}$ laser with the power density of $19.17 \mathrm{~W} / \mathrm{cm}^{2}$. 


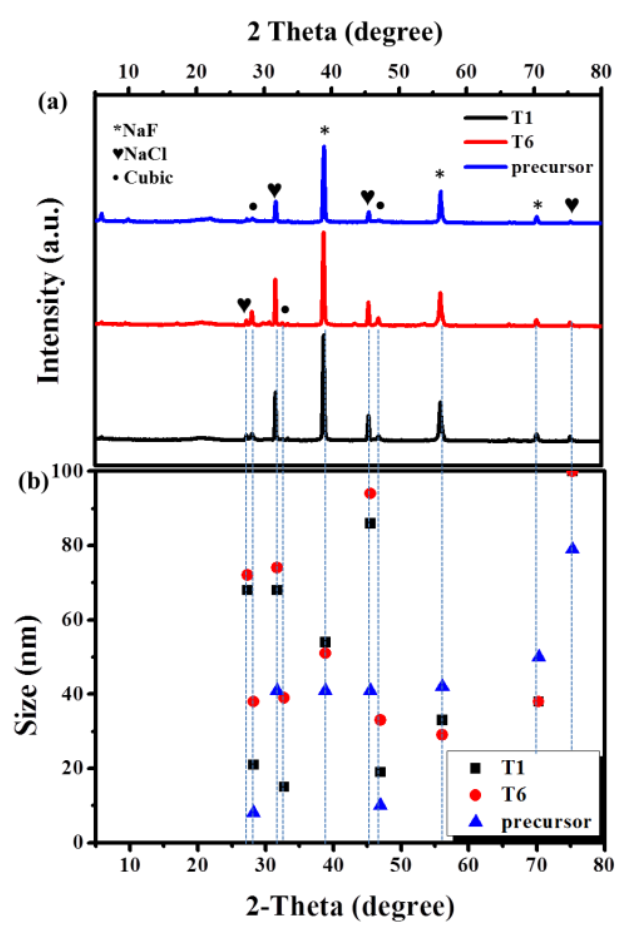

Figure S6 (a) XRD patterns of the precursors and the particles obtained after reaction for $1 \mathrm{~h}$ and $6 \mathrm{~h}$ (labelled as T1 and T6). (b) Crystal sizes of precursors, T1 and T6 calculated from Scherrer formula.

Figure $\mathrm{S} 6$ presents that the sizes of $\mathrm{NaCl}$ and cubic $\mathrm{NaYF}_{4}$ will increase and size of $\mathrm{NaF}$ will decrease as the time extending, which means the reaction occurs: $\mathrm{RECl}_{3}+3 \mathrm{NaOA} \rightarrow 3 \mathrm{NaCl}+\mathrm{REOA}_{3}$ and $\mathrm{NaF}$ will continually participate in the growth of cubic $\mathrm{NaYF}_{4}$.

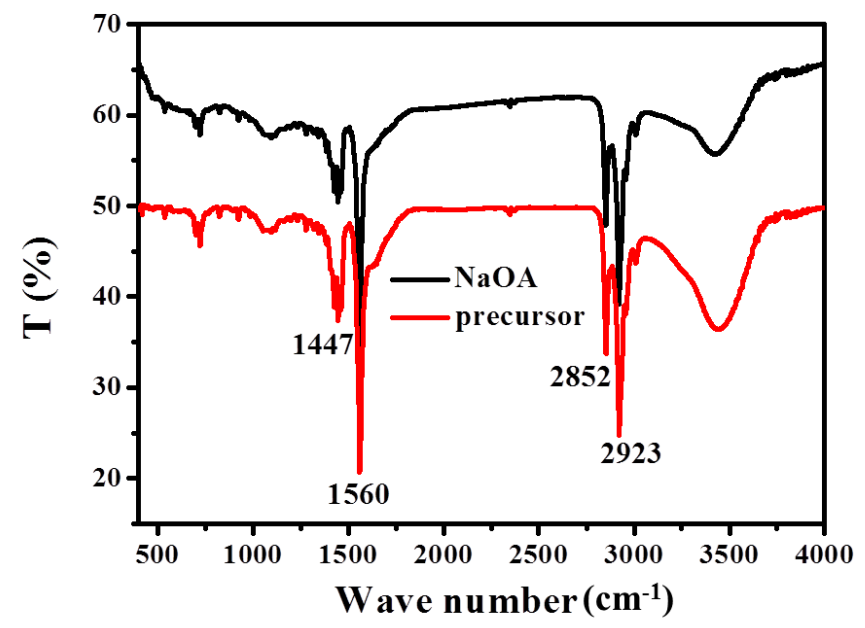

Figure S7 FT-IR spectrum of precursors and commercial NaOA.

Figure S7 shows the FT-IR transmission spectrum of precursors and commercial $\mathrm{NaOA}$ and their absorbance peaks are almost at the same wave numbers. The main 
spectral features at $2923 \mathrm{~cm}^{-1}$ and $2852 \mathrm{~cm}^{-1}$ respectively represent $\mathrm{C}-\mathrm{H}$ asymmetric and symmetric stretching vibration of methyl and methylene of $\mathrm{NaOA} .1560 \mathrm{~cm}^{-1}$ and $1447 \mathrm{~cm}^{-1}$ represent asymmetric stretching vibration of carbonyl of $\mathrm{NaOA}$.
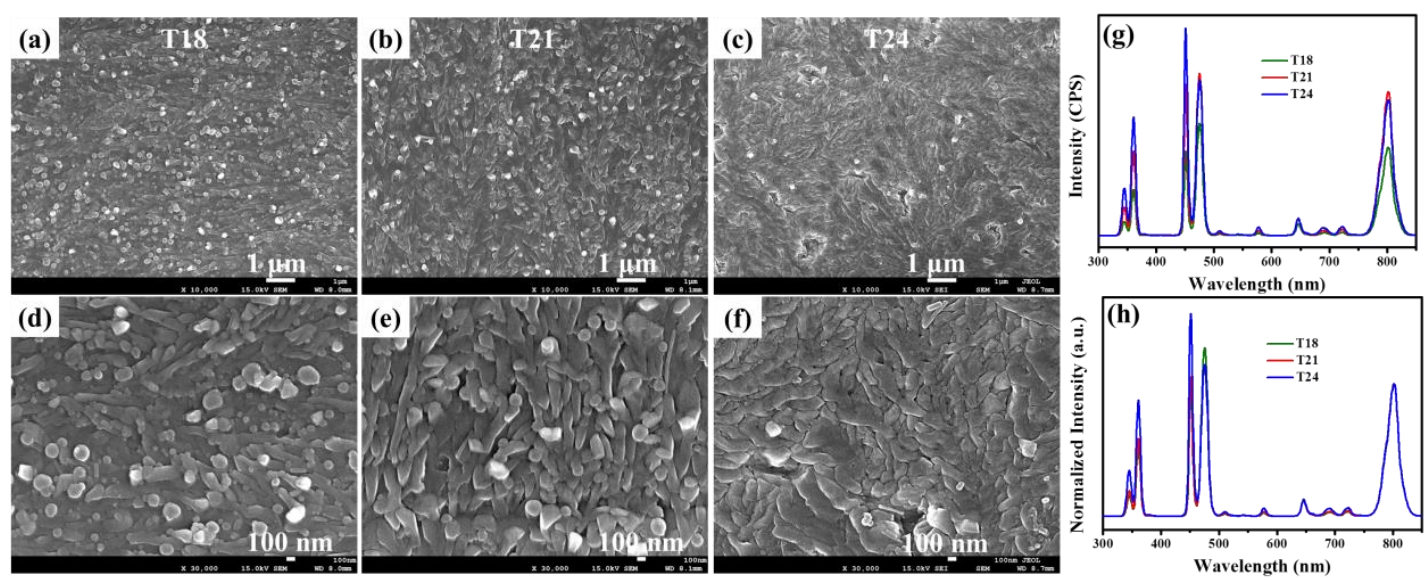

Figure S8 FESEM images of (a, d) T18, (b, e) T21 and (c, f) T24. (g) UC fluorescence spectra of T18, T21 and T24 and (h) corresponding spectra after normalized at $802 \mathrm{~nm}$.
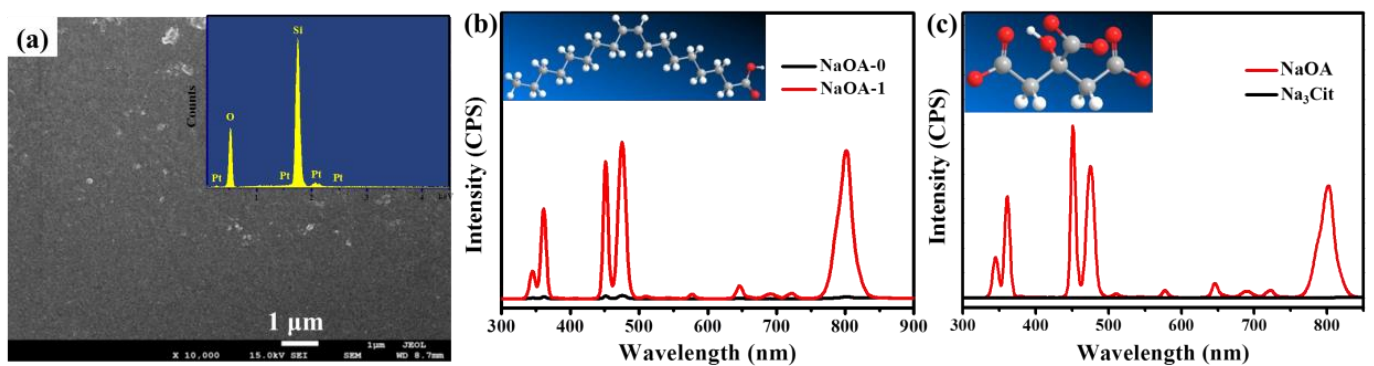

Figure S9 (a) FESEM image of $\mathrm{NaYF}_{4}: 20 \mathrm{Yb}$, 0.5Tm films prepared without surfactant $\mathrm{NaOA}$ and inserted EDS pattern. (b) UC fluorescence spectra of $\mathrm{NaYF}_{4}$ : $20 \mathrm{Yb}, 0.5 \mathrm{Tm}$ films prepared with and without surfactant $\mathrm{NaOA}$ (labelled as NaOA-1 and $\mathrm{NaOA}-0$, respectively), insert is the diagram of oleate molecule. (c) UC fluorescence spectra of $\mathrm{NaYF}_{4}: 20 \mathrm{Yb}, 0.5 \mathrm{Tm}$ films prepared with surfactant $\mathrm{NaOA}$ and $\mathrm{Na}_{3} \mathrm{Cit}$ (labelled as $\mathrm{NaOA}$ and $\mathrm{Na}_{3} \mathrm{Cit}$, respectively), insert is the diagram of citrate molecule.
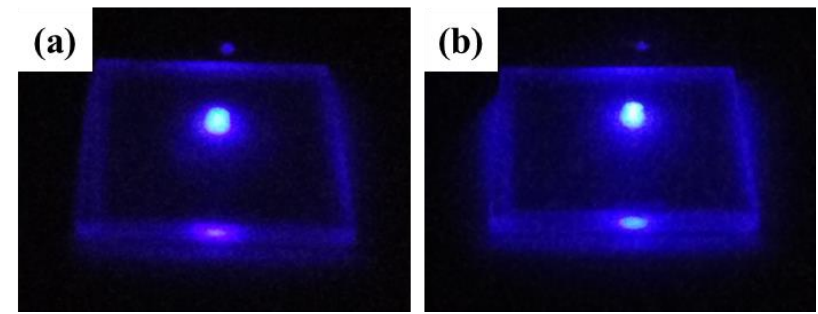

Figure S10 Digital photos of $\mathrm{NaYF}_{4}: 20 \mathrm{Yb}, 0.5 \mathrm{Tm}$ UC films irradiated with $980 \mathrm{~nm}$ laser (a) before and (b) after ultrasonic cleaning for $12 \mathrm{~h}$. 

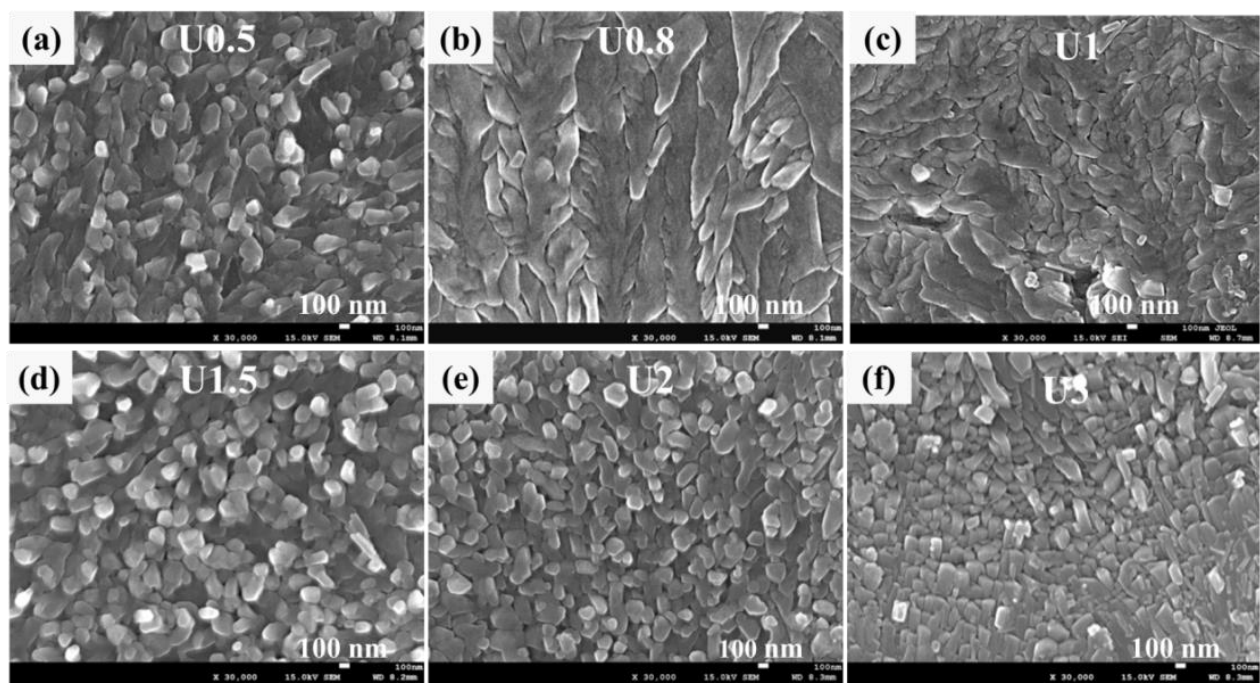

Figure S11 Central FESEM images of (a) U0.5, (b) U0.8, (c) U1, (d) U1.5, (e) U2, (f) $\mathrm{U} 3$, respectively.

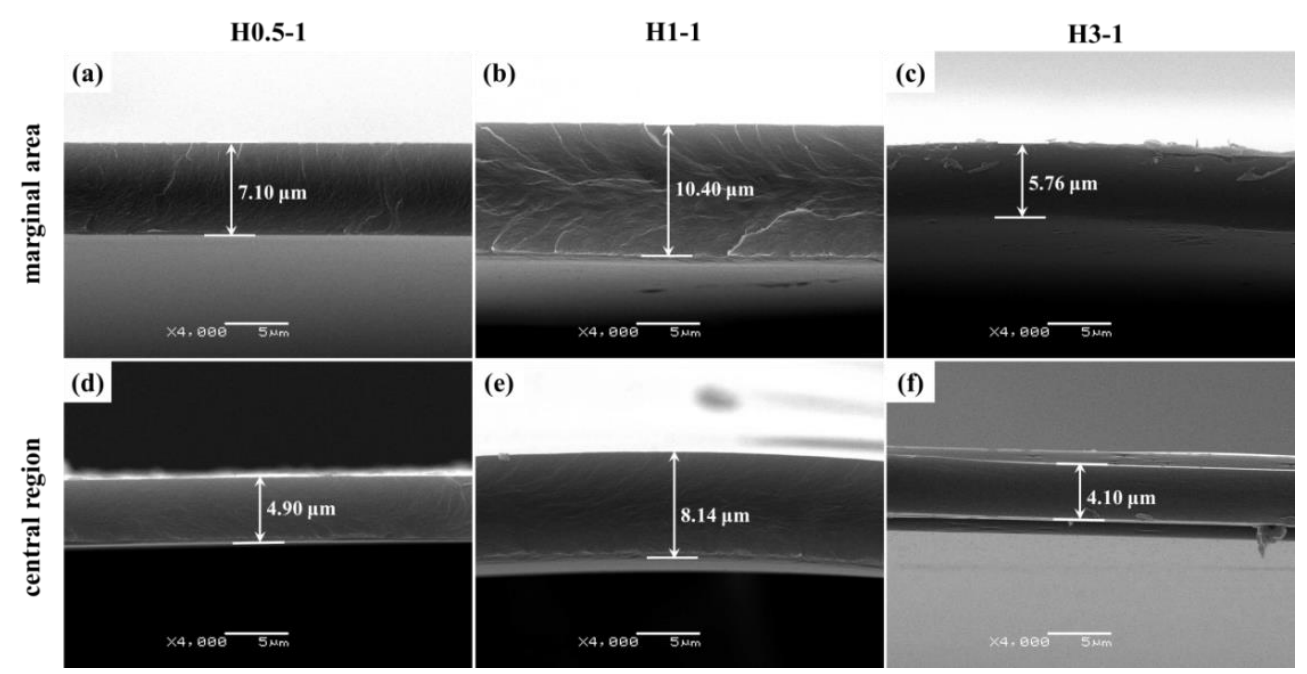

Figure S12 SEM images of cross sections of (a, d) H0.5-1, (b, e) H1-1 and (c, f) H3-1, (a-c) are marginal images and (d-f) are central images as labelled. 


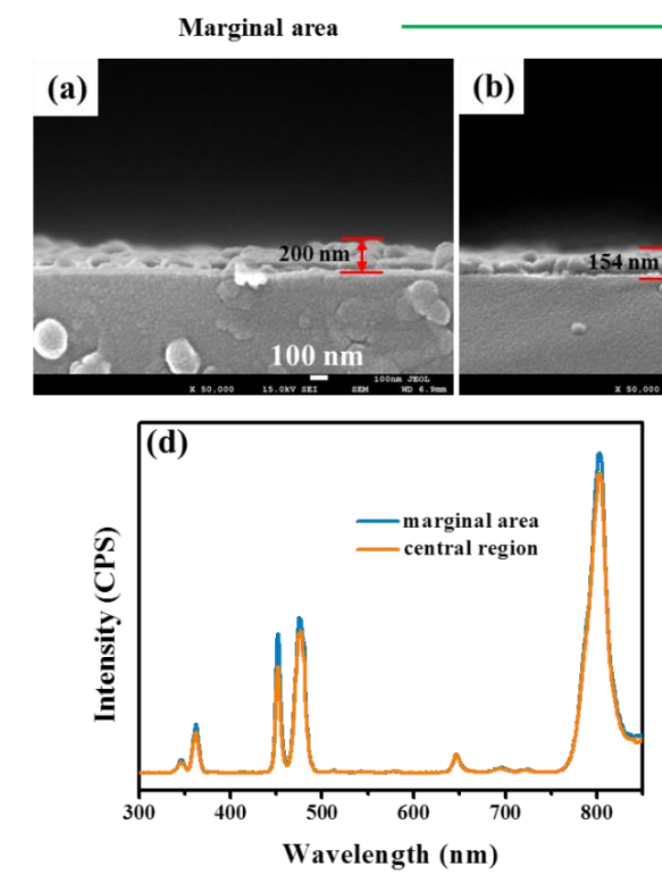

Central region

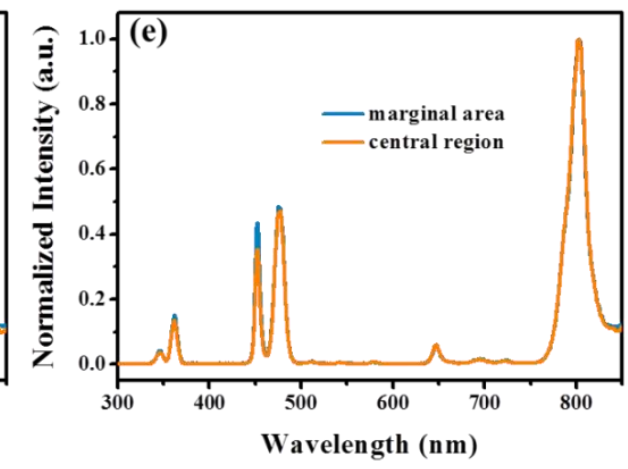

Figure S13 (a-c) FESEM images of cross sections of C3 from marginal area to central region, (d) UC fluorescence spectra of marginal area and central region and (e) corresponding spectra after normalized at $802 \mathrm{~nm}$.

(a)

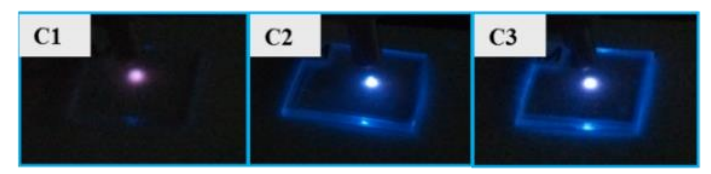

(b)

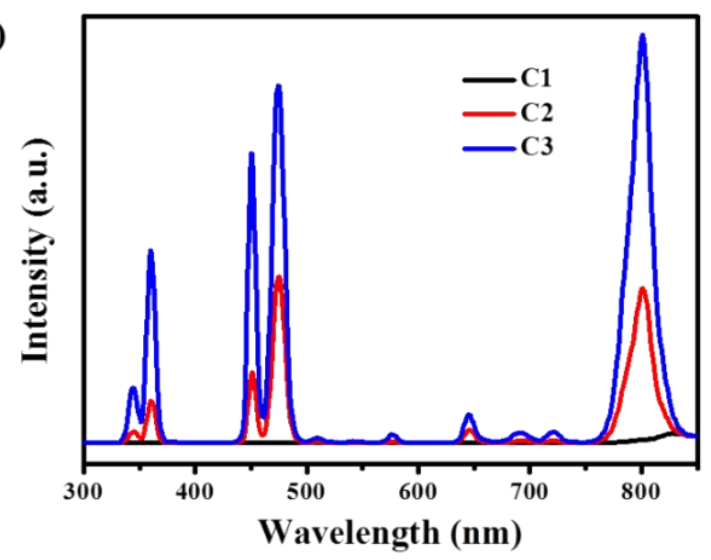

Figure S14 (a) Digital photographs and (b) UC fluorescence spectra of space-confined synthetic $\mathrm{NaYF}_{4}: 20 \mathrm{Yb}, 0.5 \mathrm{Tm}$ films $\mathrm{C} 1, \mathrm{C} 2$, and $\mathrm{C} 3$. Excitation is from $980 \mathrm{~nm}$ laser with the power density of $5.5 \mathrm{~W} / \mathrm{cm}^{2}$. 


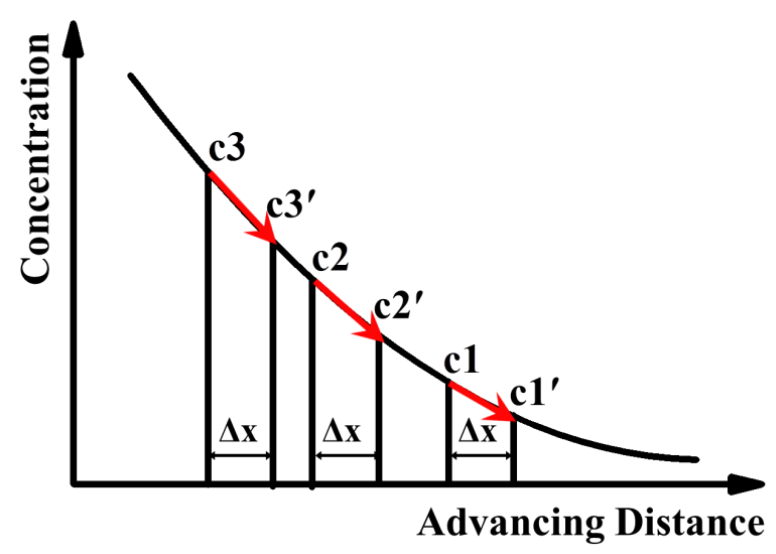

Figure S15 The relationship curve between the advancing distance and precursor concentration according to Fick' second law.
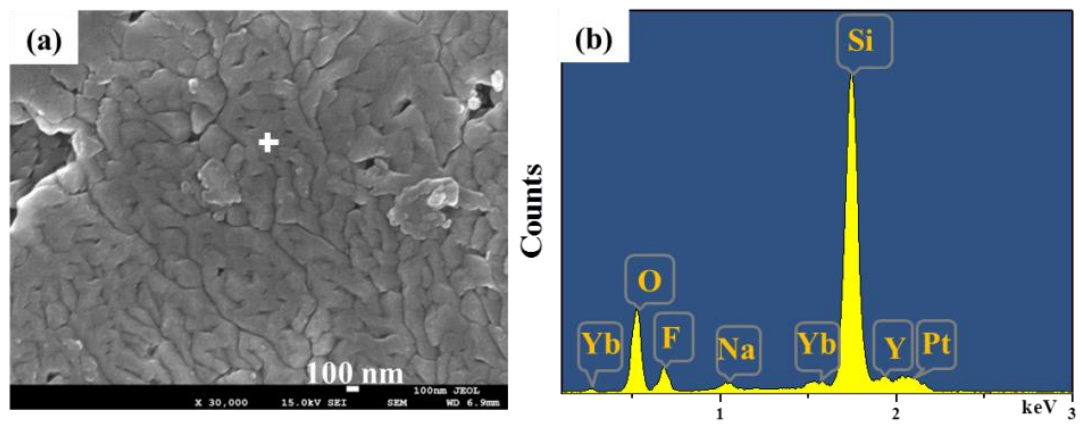

Figure S16 (a) FESEM images of space-confined synthetic $\mathrm{NaYF}_{4}: 20 \mathrm{Yb}, 0.5 \mathrm{Tm}$ UC films Mf and (b) the EDS pattern of the marked spot in (a).
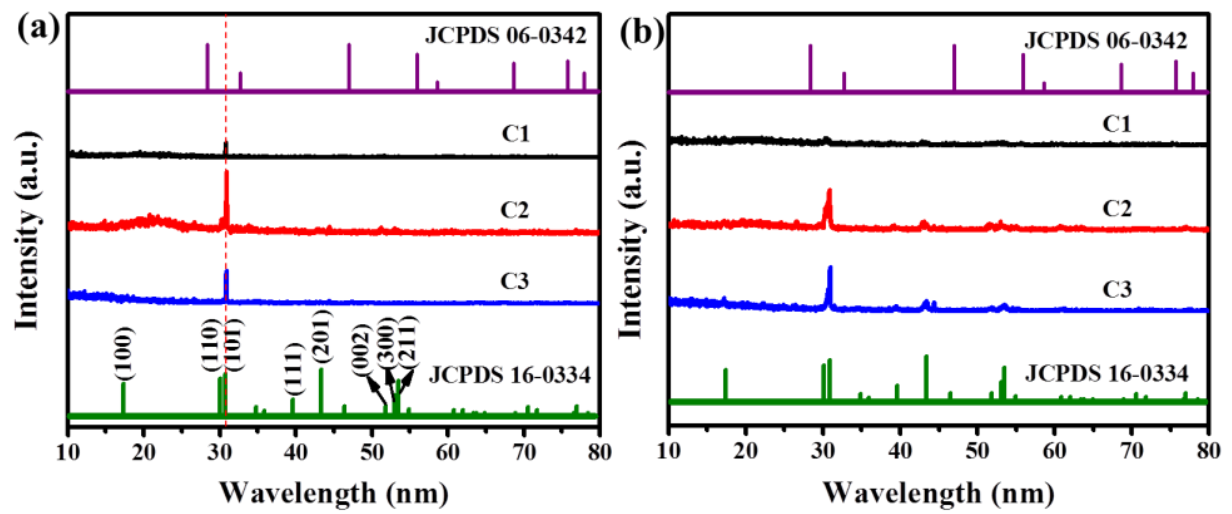

Figure S17 XRD patterns of (a) upper surfaces and (b) lower surfaces of C1, C2, and C3, respectively with standard cubic phase $\mathrm{NaYF}_{4}$ (JCPDS 06-0342) and hexagonal phase $\mathrm{NaYF}_{4}$ (JCPDS 16-0334). 

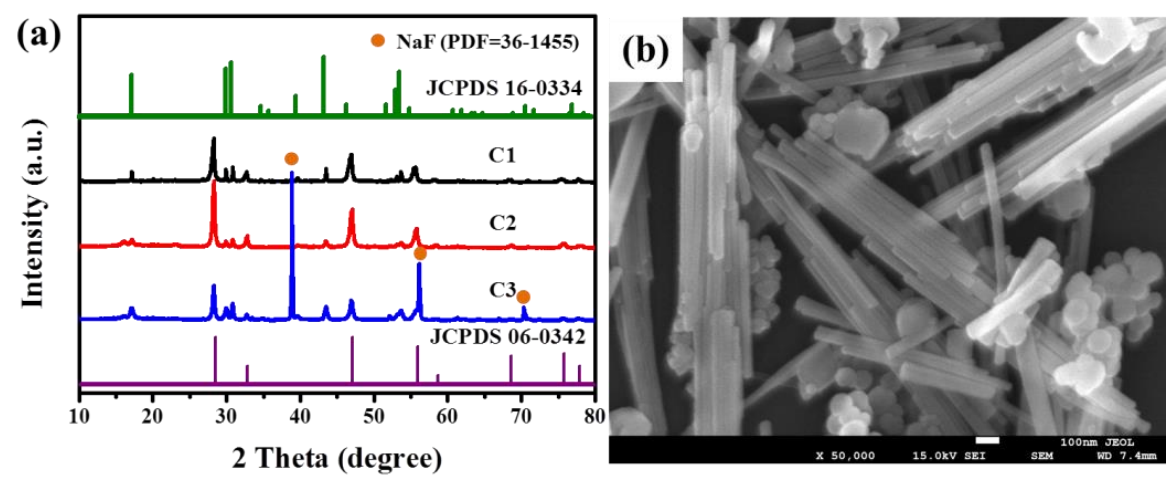

Figure S18 (a) XRD patterns of $\mathrm{NaYF}_{4}: 20 \mathrm{Yb}, 0.5 \mathrm{Tm}$ UCNPs prepared by hydrothermal method with different precursor concentrations of c1, c2, and c3. (b) FESEM image of $\mathrm{NaYF}_{4}: 20 \mathrm{Yb}, 0.5 \mathrm{Tm}$ UCNPs prepared by hydrothermal method with precursor concentrations of $\mathrm{c} 3$.
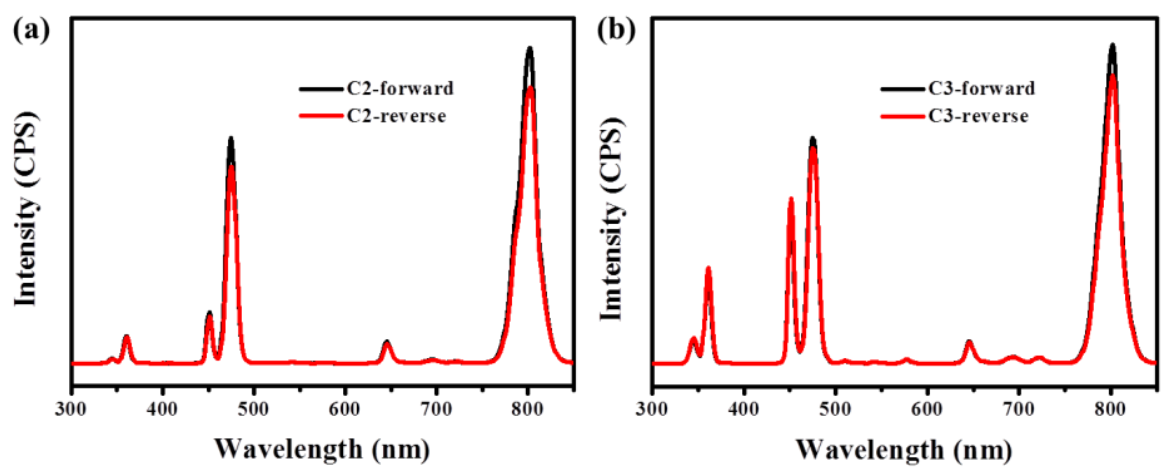

Figure S19 UC fluorescence spectra of space-confined synthetic (a) C2 and (b) C3 UC films with laser excitation forward and reverse. Excitation is from $980 \mathrm{~nm}$ laser with the power density of $5.3 \mathrm{~W} / \mathrm{cm}^{2}$.

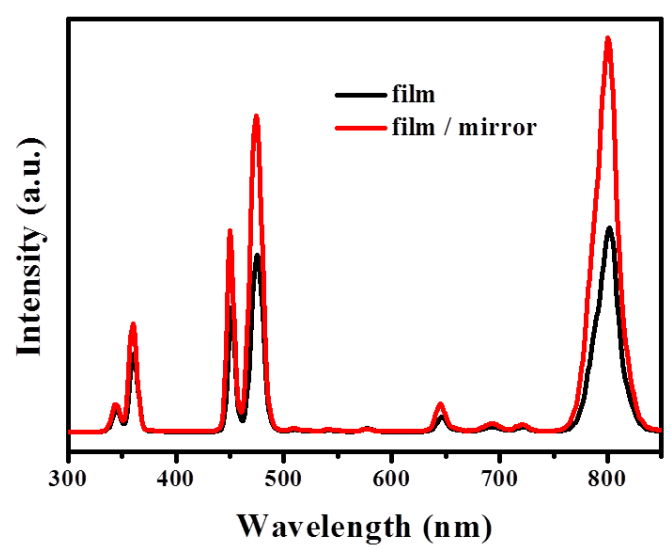

Figure S20 The UC fluorescence spectrum of space-confined synthetic $\mathrm{NaYF}_{4}: 20 \mathrm{Yb}$, $0.5 \mathrm{Tm}$ UC films with (labelled as film / mirror) and without (labelled as film) a mirror at the rear. Excitation is from $980 \mathrm{~nm}$ laser with the power density of $3.5 \mathrm{~W} / \mathrm{cm}^{2}$. 

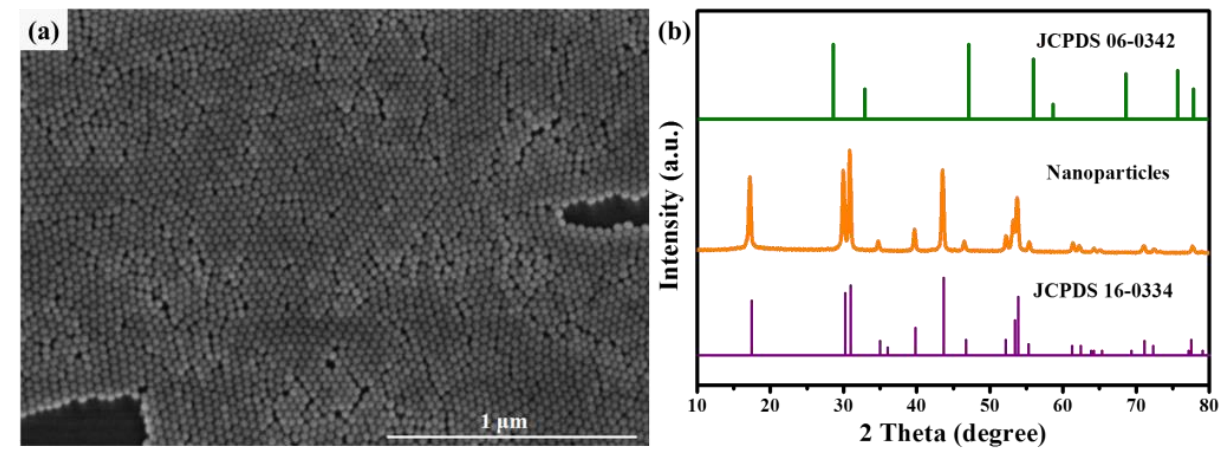

Figure S21 (a) FESEM image of self-assembly $\mathrm{NaYF}_{4}: 20 \mathrm{Yb}, 0.5 \mathrm{Tm}$ UC film and (b) XRD pattern of $\mathrm{NaYF}_{4}: 20 \mathrm{Yb}, 0.5 \mathrm{Tm}$ UCNPs prepared by thermal decomposition method.
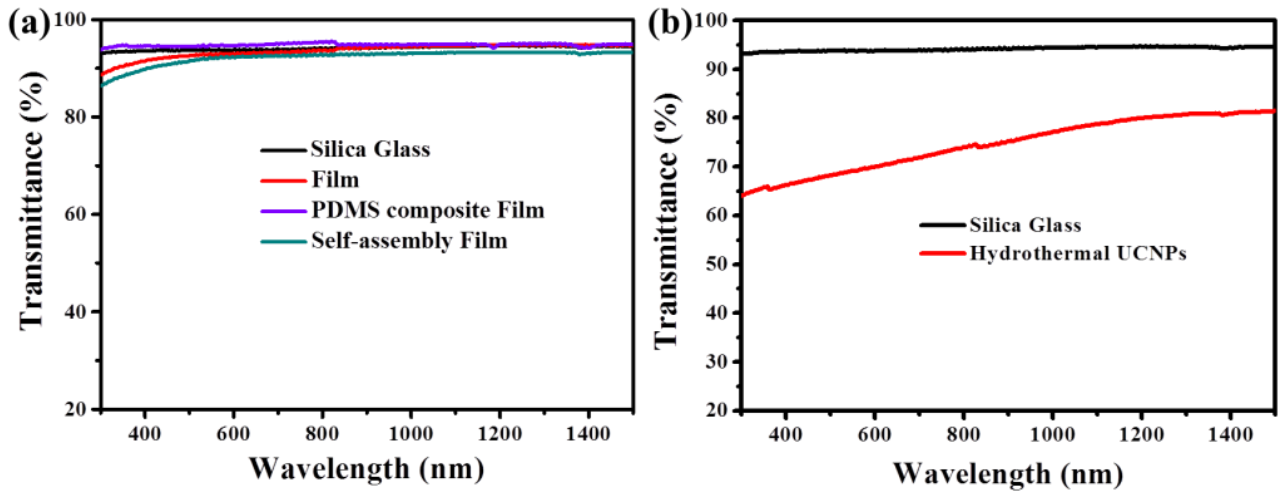

Figure S22 Transmission spectrum of (a) space-confined synthetic UC film, PDMS composite film and self-assembly film and (b) hydrothermal UCNPs. 

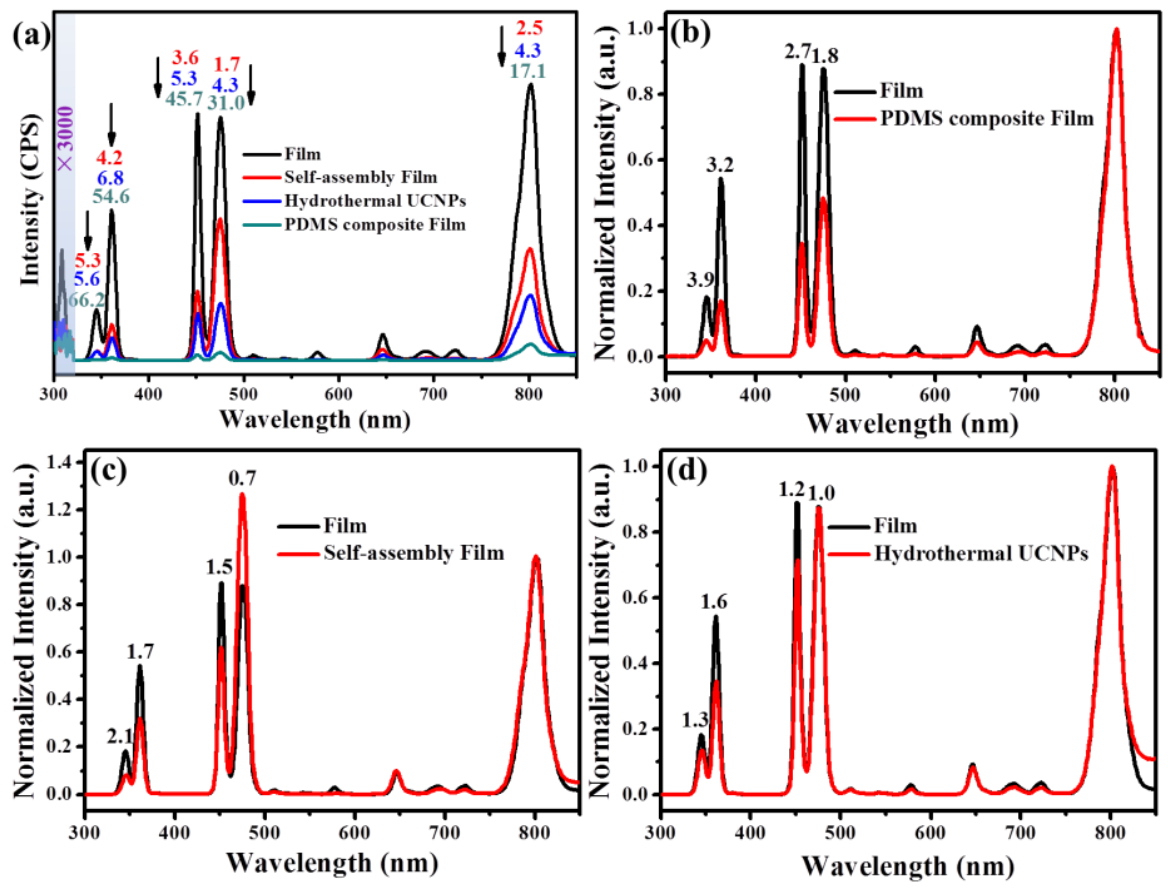

Figure S23 UC fluorescence spectra of (a) space-confined synthetic UC film, PDMS composite film, self-assembly film and hydrothermal UCNPs, (b) space-confined synthetic UC film and PDMS composite film, (c) space-confined synthetic UC film and self-assembly film, (d) space-confined synthetic UC film and hydrothermal UCNPs after normalized at $802 \mathrm{~nm}$. The numbers labelled above the peaks are the intensity ratios of space-confined film and the other UC material. Excitation is from $980 \mathrm{~nm}$ laser with the power density of $7.7 \mathrm{~W} / \mathrm{cm}^{2}$.
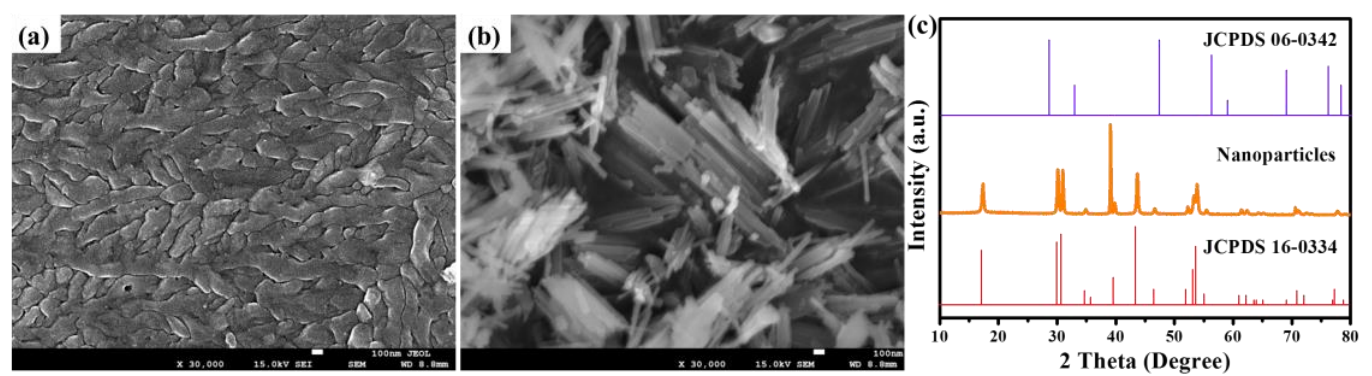

Figure S24 FESEM images of (a) space-confined synthetic UC NaYF $: 20 \mathrm{Yb}, 0.5 \mathrm{Tm}$ film, (b) hydrothermal $\mathrm{NaYF}_{4}: 20 \mathrm{Yb}, 0.5 \mathrm{Tm}$ UCNPs and (c) XRD pattern of $\mathrm{NaYF}_{4}: 20 \mathrm{Yb}, 0.5 \mathrm{Tm}$ UCNPs prepared by hydrothermal method. 

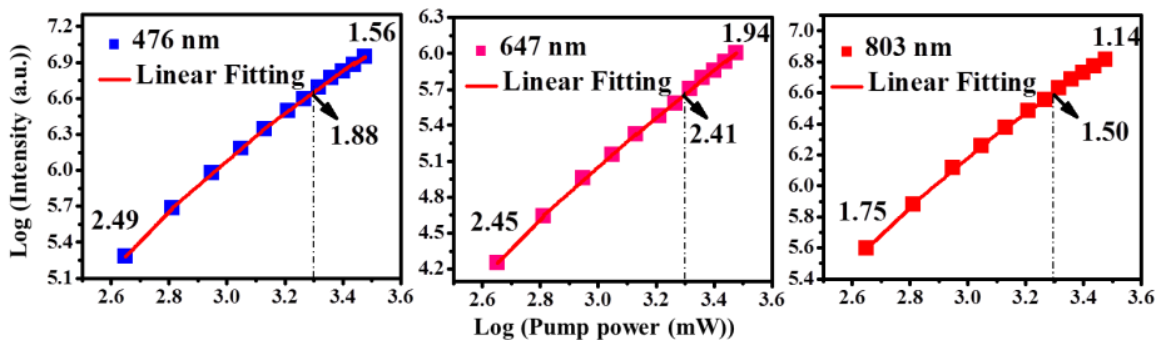

Figure S25 Log - log plots of the UC emission intensity versus the excitation power for space-confined synthetic UC film. The numbers indicate the slope at low and high pump power, respectively. The dot dash lines correspond to the highest power of Figure S27.
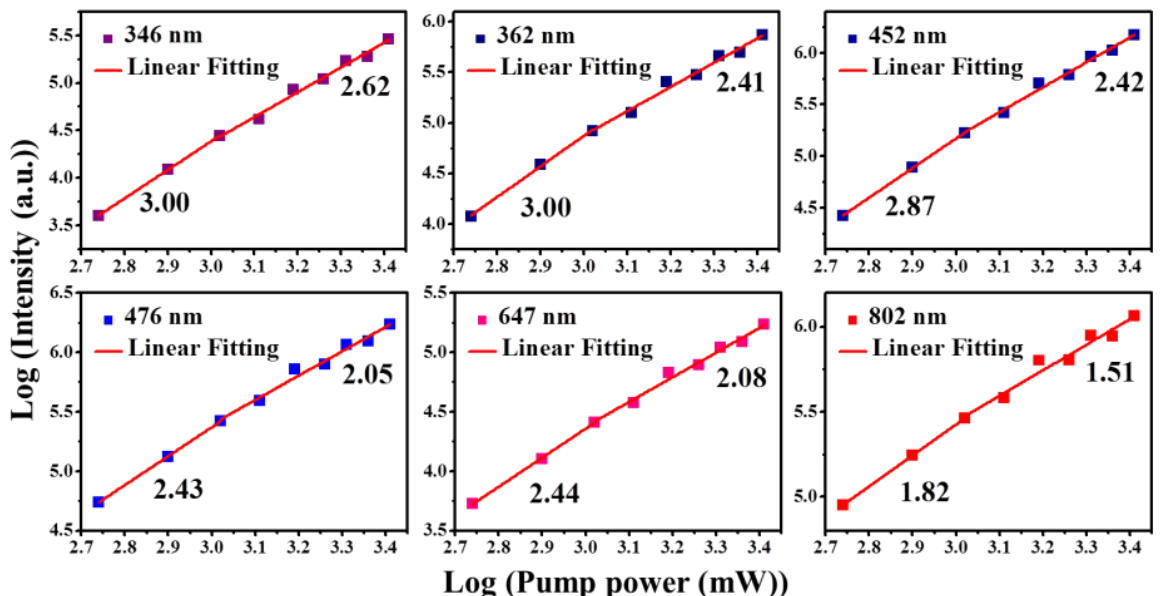

Figure S26 Log - log plots of the UC emission intensity versus the excitation power for the hydrothermal UCNPs. The numbers indicate the slope at low and high pump power, respectively.
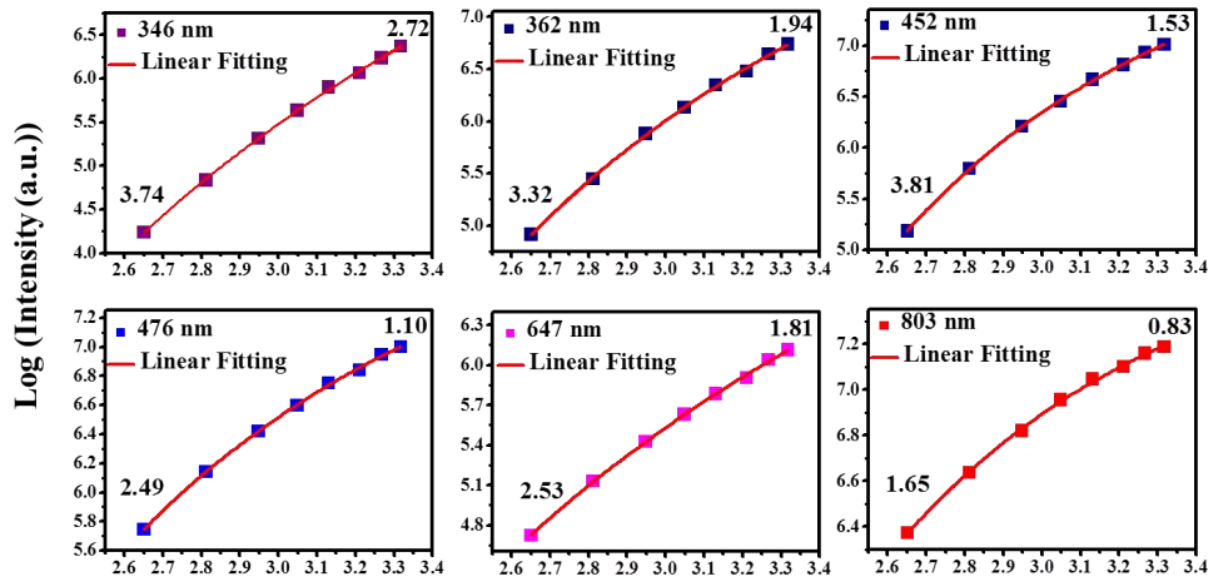

Log (Pump power $(\mathrm{mW})$

Figure S27 Log - log plots of the UC emission intensity versus the excitation power for the thermal decomposition UCNPs. The numbers indicate the slope at low and high pump power, respectively. 

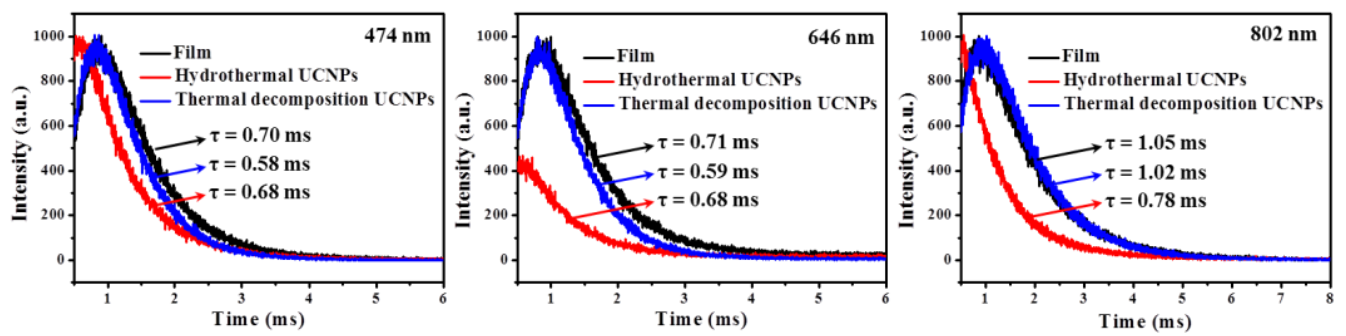

Figure S28 UC fluorescence lifetime spectra of space-confined synthetic UC film, hydrothermal UCNPs and thermal decomposition UCNPs.
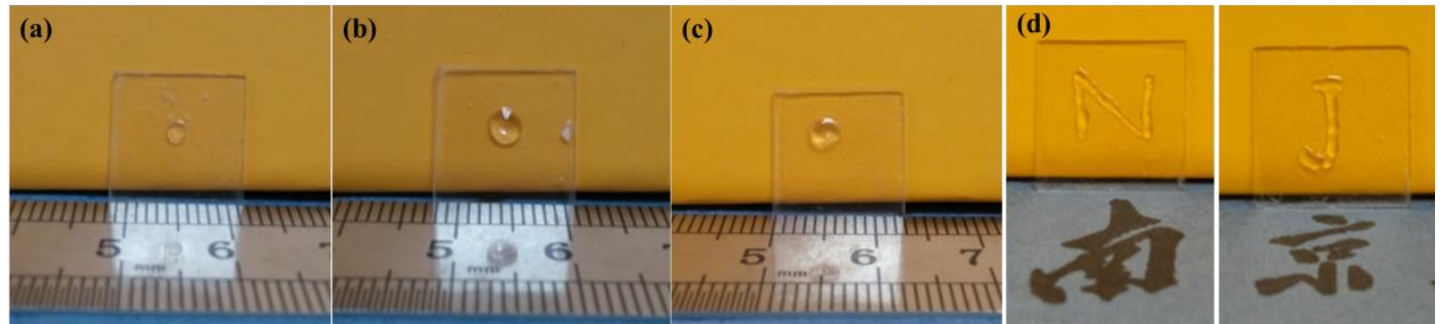

Figure S29 The photographs of NIR-induced polymerization of acrylate modified polymer under laser excitation for (a) $2 \mathrm{~min}$, (b) $5 \mathrm{~min}$, and (c) $10 \mathrm{~min}$, and (d) the photographs of hand painted letters by NIR-induced photochemical reaction of acrylate modified polymer.

(1) Dong, A.; Chen, J.; Vora, P. M.; Kikkawa, J. M., Murray, C. B. Binary nanocrystal superlattice membranes self-assembled at the liquid-air interface. Nature 2010, 466, 474-477. 